\title{
Use of the QFD method to redesign a new extrusion system for a printing machine for ceramics
}

\author{
Jihad EL Mesbahi $^{\mathrm{a}}{ }^{*}$, Irene Buj-Corral ${ }^{\mathrm{b}}$,Abdelilah EL Mesbahi ${ }^{\mathrm{a}}$ \\ a Department of Mechanical Engineering, Faculty of Sciences and Technologies, Tangier, Morocco \\ ${ }^{\mathrm{b}}$ Department of Mechanical Engineering, UniversitatPolitècnica de Catalunya, Barcelona, Spain
}

\begin{abstract}
Additive manufacturing (AM), also known as 3D printing is a manufacturing technology that takes the information from a computer-aided design (CAD) and builds parts in a layer by- layer style. Further to the extensive research on 3D printing of polymers and metals, ceramics have attracted the increasing attention of researchers, in sectors such as aerospace, electrical, chemical or medical. Complex shapes printing with porous structures, which are required in the medical area for prostheses, is difficult with most of the traditional manufacturing processes. However, additive manufacturing processes can achieve such geometries. Specifically, the direct ink writing (DIW) process is one of the most promising and inexpensive techniques for shaping free-form ceramic components. In this process, the material is extruded through a syringe and then deposited on a printing bed. In the present paper the redesign of an extrusion head for ceramics is presented. The main disadvantage of the original design was the limited volume of the syringe vessel barrel. For this reason, the proposed new system has higher capacity. For that, first the target specifications of the new extrusion system for larger material quantities were defined. For this purpose, the Quality Function Deployment method was used, in order to assure the required quality from the design phase. Then, these critical features and specifications were used to generate the different concepts that will ensure the quality of the printed parts when printing large volumes. The morphological matrix was used in this case. The work presented in this paper is the starting point of the development of the final design of an innovative extrusion head.
\end{abstract}

Keywords: Additive manufacturing; ceramics; paste extrusion; direct ink writing; hip prosthesis; extrusion head

* Corresponding author.

E-mail address: jihad.elmesbahi@gmail.com

Tel: +212 (0) 699275843

Fax: +212 (0) 539393953 


\section{Introduction}

In recent years 3D printing has rapidly gained attention across the science and engineering communities since it is a unique manufacturing technique that enables the flexible preparation of highly complex structures that are difficult to obtain using traditional fabrication methods such as casting or machining [1]. It is also referred to as additive manufacturing (AM), and this term has been accepted by the ASTM F42 Technical Committee and the ISO Technical Committee TC261 [2]. The NF ISO / ASTM 52900 standard [3] has defined additive manufacturing (AM) as the "process of joining materials to make parts of 3D model data, usually layer upon layer, as opposed to subtractive and formative manufacturing methodologies".

Further to the extensive research on the three-dimensional (3D) printing of polymers and metals, 3D printing of ceramics has attracted increasing attention of researchers, because ceramics provide low abrasion, and combined good mechanical properties[4, 5]. Today, the introduction of 3D printing technologies with ceramic in the medical field is becoming a vital necessity because of its stable physicochemical characteristics, with the low release of debris, high biocompatibility [6], and good osteoconductivity[7]. On the other hand, machining of ceramic components is difficult, owing to their extreme hardness and brittleness [1,8]. With the aid of high-quality imaging technology, 3D printing has the capability to create precise anatomic prostheses used in various medical applications[9,10]. Its implementation will allow manufacturing customized parts, which will be fixed by means of osseointegration, allowing minimally invasive surgery. Thus, this will help a wide range of disabled people affected either by an accident or a genetic deformity to carry on their normal life [11]. Prosthetic applications in dentistry offer the possibility to restore teeth and lost tooth substance by means of toothsupported crowns. Using 3D printing technology, it is possible to manufacture complexly shaped implants in large numbers, which possess excellent strength and geometric fidelity [12].

A great variety of 3D printing technologies have been specifically developed or modified to fabricate three-dimensional ceramic components. Zhang Wei et al. [1]categorized the 3D printing technologies into slurry-based, powder-based and bulk solid-based methods. Specifically, slurry-based technologies use ceramic/polymer mixtures from low viscosity (with an order of magnitude of $\mathrm{mPa} \cdot \mathrm{s}$ ) and with a low ceramic loading (up to $30 \mathrm{vol} \%$ ) to highviscosity pastes (with an order of magnitude of $\mathrm{Pa} \cdot \mathrm{s}$ ) with a much larger ceramic loading (up to 60 vol\%). In order to manufacture ceramics, either extrusion by Direct Ink Writing (DIW) or byFused Filament Fabrication (FFF), with ceramic filled plastic filaments can be used. Other processes are Stereolithography (SL), which refers to the photopolymerization of ceramic powders suspended in a polymerizable medium [11,12],Digital Light Processing (DLP) and "Inkjet-based Inkjet Printing (IJP) [13]. As for powder-based ceramic 3D printing technologies, they mainly utilize powder beds normally containing loose ceramic particles as feedstock. Three of the most well-known processes are three-Dimensional Printing (3DP) [14], Selective Laser Sintering (SLS) [15], and Selective Laser Melting (SLM)[16,17]. Regarding bulk solid-based technologies, the method Laminated Object Manufacturing (LOM)has also been used [1]. The application of this technique to ceramics manufacturing was first demonstrated by Griffin and co-workers in 1994 based on tape-cast alumina and zirconia green sheets [18].

In the present research, slurry-based technologies with extrusion methods were employedto print prostheses, in which ceramic powder mixed with a polymer. Specifically, Direct Ink Writing (DIW) was used, since it allows freeform fabrication of ceramic components due to its simplicity, low cost of their fabrication system, high density of the fabricated parts, and its capability of producing parts with multiple materials [19]. According to the literature 
review[2,18,19,20,21,22], 3D printing extrusion machines for ceramic paste or ink can be categorized into three constructive designs, plunger-based, screw-based, and pump-based extrusions machines. Regarding the plunger extrusion, several open-source designs have become available online for retrofitting consumer 3D ceramic printers. For example, the Universal Paste Extruder by RichRap[23], and the ZMorph Thick Paste Extruder [24]. The second constructive design uses an auger screw to push material through the nozzle [19]. Other extrusion mechanisms that work with pumps, for example [25] show the conception, design, and materialization of a pumping-based extrusion system.

QFD has been used in industry to design different components: in the automotive industry for car design [26], in the construction industry, for example for processing the customers' requirements[27, 28], or in the food industry[29, 30], among others.As for additive manufacturing equipment,Da Silva et al. used the fuzzy-QFD approach to develop a 3D printer. They found the relationship between the customer demands and the technical requirements[31]. Caligiana et al. used QFD to validate the design process of an open mold that will help combine additive and subtractive technologies[32].Efstathiadiset al. used QFD to improve the design of a 3D printed surgical instrument[33]. They used QFD to translate the requirements into precise technical specifications.Cordeiro et al. present benefits of using QFD as a project manager tool and the easiness to implement the proposed method, using standard resources[34].Thayla et al. propose an integrated approach to support the early phases of the PSS design process that takes into consideration stakeholder requirements and sustainability issues based on quality function deployment (QFD) [35].

The main contribution of this work is the development of the first stages of the mechanical redesign of an extrusion system for a $3 \mathrm{D}$ printer, which comprises the syringe and the mechanism that provides the necessary pressure to extrude the paste. One of the main disadvantages of the original design was the limited volume of the syringe vessel barrel. To achieve the development of the new extrusion head for ceramic with higher capacity, a rigorous customized product development process was performed, based on design tools, techniques and methods available in the literature[34,35,36,37].

The first aim of this work is to obtain the target specifications of the new extrusion system for larger material quantities. They were identified by means of the Quality Functional Deployment (QFD) method. It is a matrix analysis that provides design information, including critical engineering specifications that will make the product successful [40]. The second goal was to use these critical features and specifications to generate concepts that will lead to an innovative extrusion head with the method of morphological analysis. The morphological matrix was employed in this case.

The paper is organized as follows. Section 2 presents the methodology employed to achieve the development of the custom extrusion system, as well as all the design tools and techniques chosen, the opportunity identification, and the constraint for the implementation. To generate the target specifications and concepts that will satisfy the needs, the method QFD and the Morphological Matrix are explained. Subsequent section 3 provides the evaluation results. The conclusions and prospective works are finally drawn in the last section.

\section{Methods}

\subsection{Design methodology}

When solving a design problem, it is recommended to use a design process, since, although the need is perceptible, the solution is not predetermined, and several viable solutions may be plausible. There are many different approaches to the design process, but they all encompass the 
aspects of research, synthesis, creation, and reflection [41]. For example, the product development process comprises three phases[42]: analytics, which includes identifying the need, identifying the problem, and collecting information; creative, which contains concept generation and decision making; and executive, which includes the engineering details as well as the implementation. Pahl and Beitz[38] propose a decomposition of the product design process in four phases (product planning, conceptual design, embodiment design, and detail design). Other variants of the design process include five phases (define the problem, gather information, generate multiple solutions, analyze, and select a solution, and test and implement solution) [43] or six phases (planning, concept development, system-level design, detail design, testing and refinement, and production ramp-up) [36]. Specifically, in the present paper a previously presented customized product development process was used (Fig. 1)[38].

This paper is devoted to the second step of the product development process named "functional architecture" with the application of the Quality Function Deployment (QFD) to generate the target specifications. Then, the morphological matrix, corresponding to the third step, was applied, in order to generate the concepts that will satisfy the requirements.

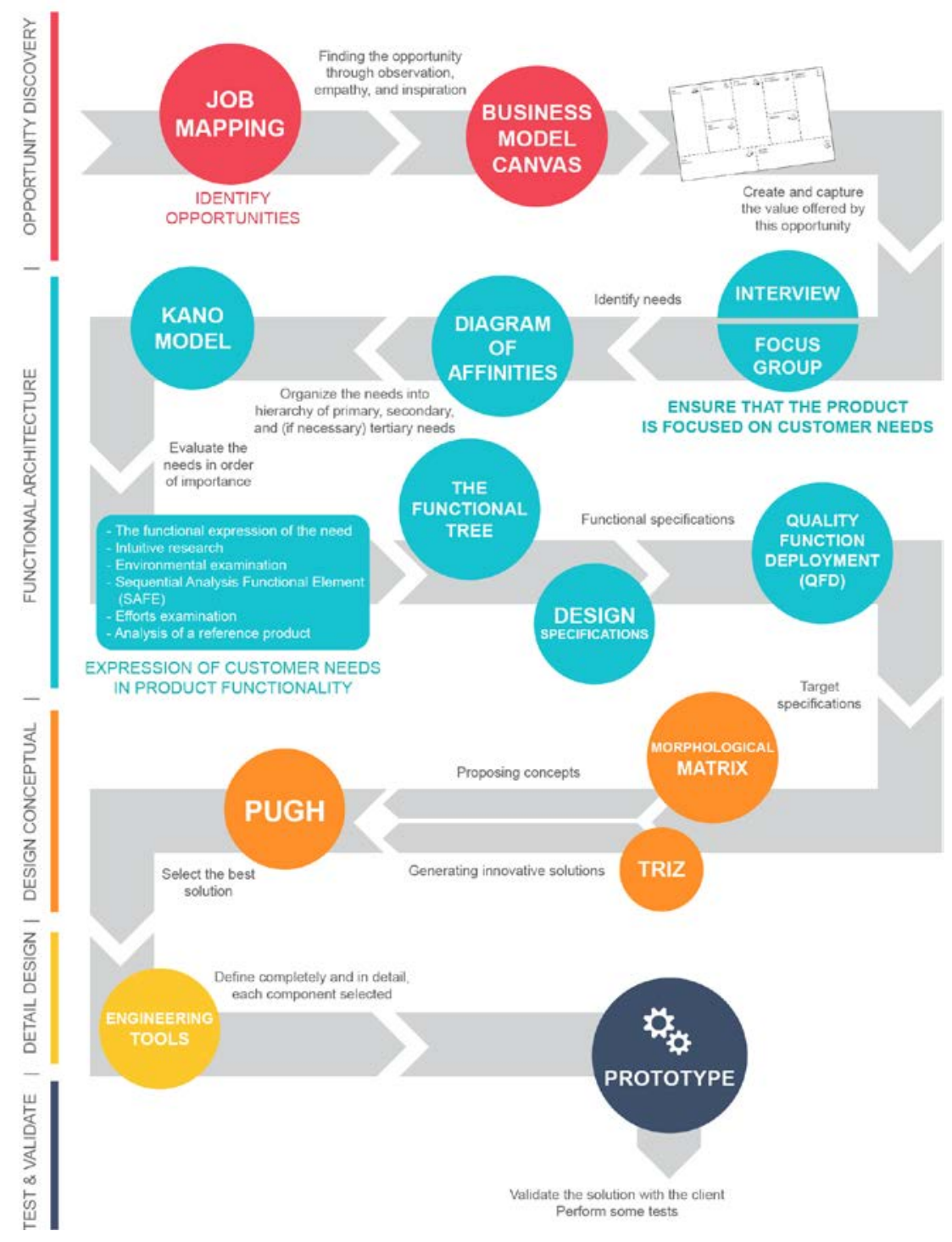

Fig. 1. Proposal of a custom process to develop a new head extruder [40] 
The design process begins with a definition of the problem and the discovery of the opportunity to develop a customized extruder machine for the 3D printer that can printa broad range of parts in ceramic material. In the first step, job mapping is recommended, inspired by the Jobs to be Done methodology[44], because a good definition of a problem in design implies a good enumeration of the requirements relating to both the customers and the product to be designed, in this case,the extruder's head. In the next step, once the needs of the customer are clearly identified, it is necessary to determine the essential functions of the machine to meet these requirements. Product design information such as functional and target specifications of the product is collected by means of Quality Function Deployment (QFD)[45]. A study of competing products on the market should be conducted at this stage. Once this phase is over,the design phase starts. It consists of exploring the initial design problem (specifications) and generating solution concepts that meet the design requirements, with the help of the morphological analysis[46]. Once the concepts of the customized extruder machine are generated, a Concept Selection Process is used to iteratively select the best concept from the concepts found with the Concept Selection Matrix (or Pugh Matrix)[39]. The analysis step allows detailing the design by making a complete study of the solution. It results in an identification of the final design that best fits the product requirements, to explain all the technical characteristics of the extruder. After this step, the construction of a prototype of the design will be tested and checked to see if any modifications are necessary. It is finally important to emphasize that the design process is iterative at every step. Indeed, it is possible to return to a previous step if adjustments are deemed necessary, as well as to ensure the results' effectiveness.

\subsection{Identification of the need}

Before starting the design of the product, the real need, and the main functions of the system were established (Fig. 2). In order to clearly define the need of the customers, the main need for printing hip prostheses in ceramic material was determined.

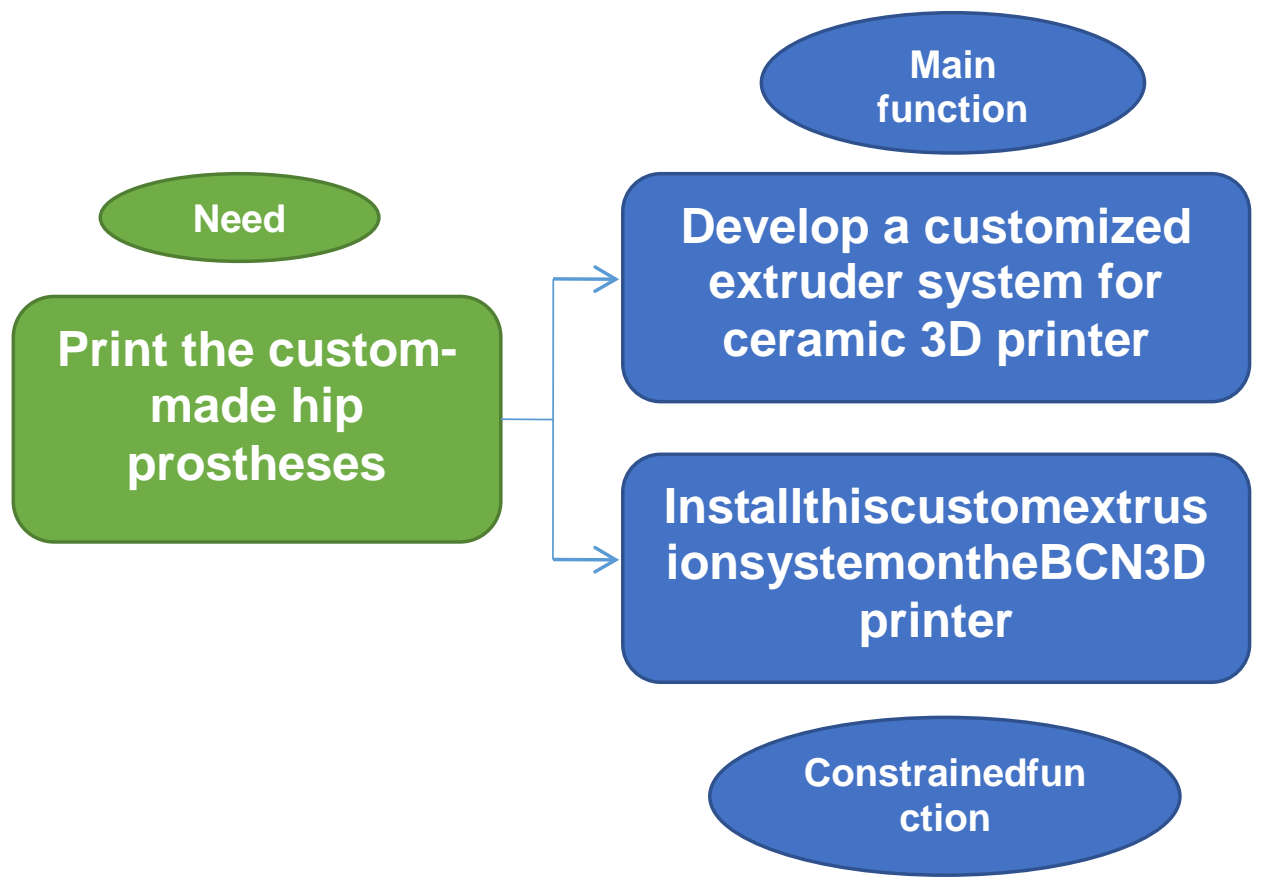

Fig. 2.Functional decomposition of the need 
Customer needs are usually expressed in "customer language". However, if these expressions help to develop a clear sense of customer interests, they provide little information on how to design the product. Indeed, they leave a wide margin for subjective interpretation. For this reason, other specifications need to be established that detail what the head extruder is supposed to do in a precise and measurable way. Product specifications do not inform about how to meet customer needs, but they provide a precise description of what the product is supposed to do. There are several techniques to generate the engineering specifications and, specifically,to target the functional specifications that have the greatest possible impact on meetingcustomer expectations. One of the most employed techniques to generate critical specifications is the Quality Function Deployment (QFD) technique.

\subsection{Identification of the target specifications using $Q F D$}

Quality Function Deployment (QFD) method relies on a matrix deployment with several matrices. It is primarily used when launching a new product when there are many choices available to designers. It allows answering specific questions, such as what the expectations to be met in priority to ensure the commercial success of the product are, what the technical answers to work are, and what the critical points to consider are.QFD allows, right from the launch of the product, to target the elements which could arise and could have a negative influence on the product, in order to be able to avoid them. The quality house is used to include the quality of the product, as quickly as possible, within the various development processes and, thus, to ensure to have a quality product from the design stage. The method allows to collect and analyse the customer's voice, to develop products with higher quality that meet or surpass customer's needs [47]. It allows translating the customer demands into accurate technical requirements. In fact, the extent of areas where QFD has been used has become so exhaustive that it is a research topic itself[46,47,45].

The QFD method is based on the "Whats-Hows" matrix, which is called the House of Quality (HOQ). The HOQ[28] (Fig. 3) documents and establishes all the processes to implementQFD. It uses four matrices:

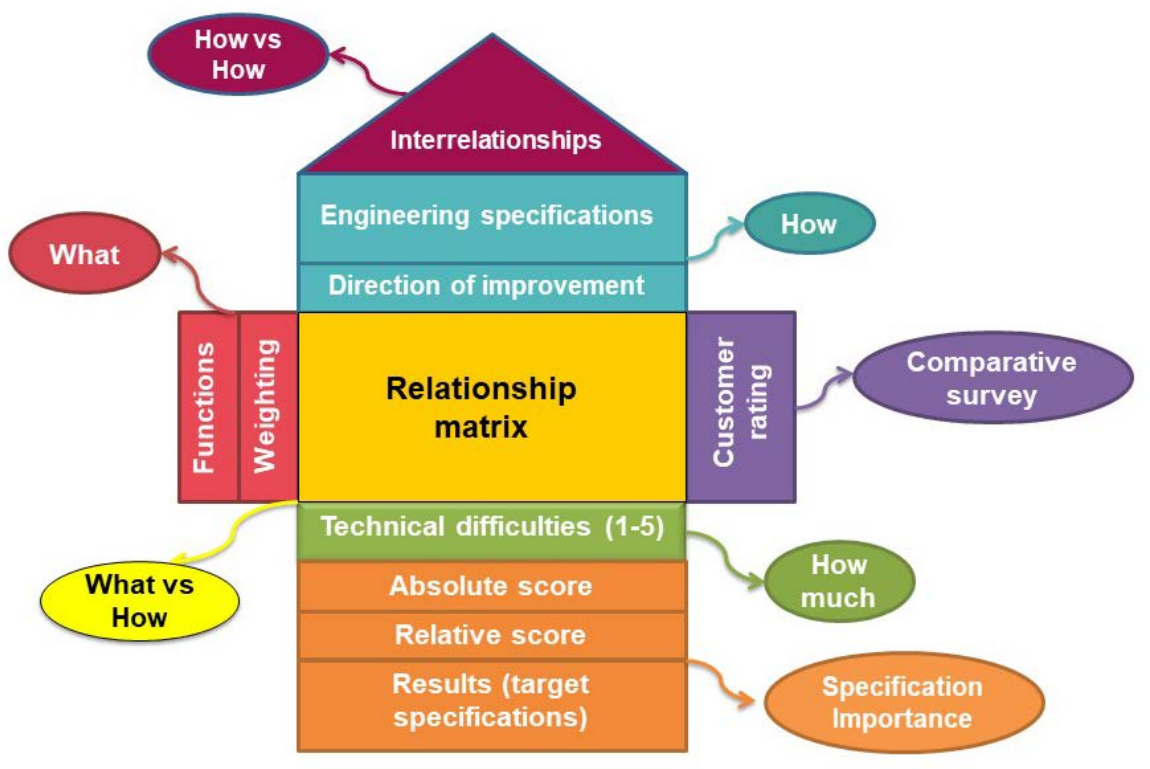

Fig. 3. The House of Quality (HOQ) adapted from [36] 
Product planning is the first matrix, the second matrix relates potential product features to the delivery of performance characteristics, and process characteristics and production requirements are related to engineering and marketing characteristics with the third and fourth matrices respectively[50]. This paper is focused on the first matrix. The construction of the quality matrix is described below:

What: The first goal of the QFD method is to determine what is to be designed. It is about writing a list of the customer's needs and their weighting. To build this matrix, first the functions derived from the needsare used, as well asall those that can make it possible to compare similar products to each other, to fill the rows of the matrix. The functions should not be too detailed for the customer to be able to evaluate the level of achievement of this function in different products during the comparative survey. In addition, goals and requirements are considered as the customer's needs.

Weighting (1-5): The weighting column represents the values determined for the needs and associated functions, which scores the weighting factor assigned to each one of them (1 corresponds to the less important function).

How: Once the WHATs (customer's requirements) are generated, it must be analyzed how to satisfy them. In this second stage, the means of achieving these WHATs is identified and termed as HOWs. Therefore, HOWs are the design (or technical or product) characteristics that serve to meet the WHATs[51]. Incidentally, the engineering specifications that will appear in the columns of the matrix are all attributable to at least one of these functions. On the other hand, a function can generate several specifications. It must indicate the orientation for each specification. 3 criteria orientations are possible: Maximize the level ( $\uparrow$ ), Minimize the level $(\downarrow)$, and get the desired level (o).

How much: In this third step, it is necessary to rate the technical difficulties of the specifications that set against the experience of the members of the design team on a scale of 15 or with respect to the limitations of existing products. The list of HOW MUCH is used to characterize the HOW.

What vs How: To estimate the relative importance among the requirements defined above, the relation matrix is used. In this central section of the DFQ matrix, the functions (lines) are noted according to their strong relation (9), their average relation (3), their weak relation (1) or the absence of relation ( 0 or empty box) with the specifications (column). It indicates how product characteristics or decisions affect the satisfaction of each customer's needs. It consists of relationships existing between each WHAT and each HOW attributes.

How vs How: It is the roof of the HOQ and represents the interdependencies among HOWs. It can play an important role in deciding on the number of HOWs that directly affect the cost, prioritizing WHATs and HOWs[51]. The specifications made to satisfy the customers are sometimes contradictory. Therefore, in this part all positive relations (indicates that the optimization of a specification will have the same impact on another specification) and negative (the optimization of one specification leads to a compromise on another) between the different criteriaare identified.

Comparative survey:It consists ofmaking a comparative evaluation of the competitors between each of the requirements (WHAT). As David G. Ullman wrote[52]in the process design there are different products that can fill the same need. For this reason, it is recommended to study existing products, both because it creates an awareness of what already exists (the "now"), and because it supplies opportunities to improve the existing design.

Specification importance: At the final stage of the quality house, it is necessary to identify the importance of each specification regarding customer satisfaction. If a target is important, then effort needs to be expended to meet the target. If it is not important, then meeting the goal 
can be more easily relaxed. In the development of products, it is seldom that all targets can be met in the time available and so this effort helps guide what to work on[52].

The method to find importancesis presented next:

- The level of absolute importance: multiplying each cell's value by the weight of the customer demand and totaling the column for each quality characteristic.

- High relative score (PR): the rating of 1 or 0,1 being attributed to a high PR (arbitrary choice).

- The level of technical difficulty (DDT): the rating of 1 for values of 4 or 5

- Priority: the rating of 1 if the specification is derived from a function that has been identified as a design priority in the comparative survey.

The total score for each column indicates the importance of that characteristic in measuring the customer's satisfaction[53]. Therefore, a rating of 3 indicates that they are critical specifications for customer satisfaction.

\subsection{Generation of concepts using the morphological matrix}

A product concept is a rough description of the technology, shape or principle of operation of a product. It is a concise description of how the product will satisfy the needs of the customers. A concept is generally expressed in the form of a diagram and is generally accompanied by a brief text description.

The goal in this step is to propose concepts for each subsystem of the extruder system with the morphological analysis. It is an inventive designing method, because its products may be novel design concepts, i.e. concepts that are unknown, useful, and feasible[46]. This technique is carried out in 2 stages. The first step consists of listing the functions that must be satisfied by the product and in breaking down the system into subsystems in order to facilitate the generation of concepts. The second step is finding the maximum of possible concepts thatcan be generated by each identified function or each subsystem in the decomposition.

\section{Results and discussion}

\subsection{Identification of the need}

The printer used in this project is a Dual Paste Extruder printer. It is a modular printer developed by CIM-UPC, which belongs to the Universitat Politècnica de Catalunya (UPC)BarcelonaTech group. Its extruder mechanism consists of a rack-and-pinion system that directly pushes the syringe plunger and transmits the necessary force to operate it (Figure 4). It is driven by a motor and gears set to reduce the speed of rotation and multiply the torque. The rotary movement is ensured by the stepping motor and it is assigned to the gear wheel. The speed of rotation of the wheel 1 is reduced by a normal four-stage reduction gear. The last toothed wheel has meshed with the rack. The latter applies a pressing force on the surface of the piston and drives it in vertical translation to ensure the extrusion of ceramic paste. This injection system controls the amount of material deposited through the pressure exerted. The extrusion unit also contains a syringe and a tip. 
Fig. 4. Extruder mechanism the Dual Paste Extruder ceramic printer.

However, the extrusion system only allows printing low volumes under $5 \mathrm{~cm}^{3}$ of ink. In order to print ceramic prostheses, higher volumes are required.

In the next subsections, the results of the two first steps of the design process of a new extrusion system for printing higher volumes of ink are presented.

\subsection{Application of QFD to the extruder system for ceramic 3D printing}

In this project, the client is initially the person who manufactures ceramic prostheses or any other printed part. However, the term customer includes all the people who have to contribute to the design of the system: buyers, technicians, engineers, research professors, employees, manufacturing, and marketing services, etc. Fig. 5 shows the Quality Function Deployment (QFD) and the coming section explains each step that was followed to fill the matrix.

Step 1: Customer Requirements - "Voice of the Customer": Once the needs of the customers were identified in the previous part, the characteristics of the solution that will respond to these needs were defined. These characteristics are the functions. As noted in the previous section, this first step requires obtaining and expressing what the customer truly wants and not what we think he or she expects [54]. For this, the approach used is Functional Analysis using a competitor's analysis of technical data, observations, surveys, focus groups, engineering judgment as well as various analysis techniques. It enabled us to make an inventory of the main features of the solution. Table 1 shows the main functions and the constrained functions of the head extrusion to be designed.

After listing the customer demands, a design team assigned a weight indicating the relative importance of each request (Customer Importance Ratings). The weights are generally Based on given Likert scale from 1 to 5 , as $1=$ Not important; 2 = Quite important; 3 = Important; $4=$ Very Important; 5 = Most Important.

Product specifications do not inform the team about how to meet customer needs but represent a compromise on what the team will attempt to achieve and meet customer needs, and that is the goal of the next step. 
Table 1.

The main functions and the constrained functions of the custom head extrusion

\begin{tabular}{|c|c|}
\hline Function & Definition \\
\hline $\begin{array}{l}\text { Print hip prosthesis and various ceramic } \\
\text { parts }\end{array}$ & $\begin{array}{l}\text { The extruder makes it possible to print prostheses and a } \\
\text { large range of the ceramic parts }\end{array}$ \\
\hline $\begin{array}{l}\text { Install the extrusion system on the } \\
\text { BCN3D machine }\end{array}$ & The extruder must attach to the BCN 3D machine \\
\hline $\begin{array}{l}\text { Be easily adaptable to other types of } \\
\text { machines }\end{array}$ & $\begin{array}{l}\text { The extruder to be developed must be modular, flexible and } \\
\text { configurable }\end{array}$ \\
\hline $\begin{array}{l}\text { Increase machine productivity and quality } \\
\text { of printed parts }\end{array}$ & $\begin{array}{l}\text { The extruder to be implemented must be efficient; effective } \\
\text { in terms of achieving objectives, but at an optimum time }\end{array}$ \\
\hline Allow flow stability & $\begin{array}{l}\text { The flow control used for printing has a very important } \\
\text { impact on the quality of the parts }\end{array}$ \\
\hline Use a standard energy source & $\begin{array}{l}\text { The solution must use standard energy so as not to increase } \\
\text { the price and also for the availability of the energy in all } \\
\text { laboratories }\end{array}$ \\
\hline $\begin{array}{l}\text { Facilitate setting and holding of the } \\
\text { syringe }\end{array}$ & $\begin{array}{l}\text { The assembly and disassembly of the syringe must be done } \\
\text { easily and correctly }\end{array}$ \\
\hline Allow stability of the syringe & $\begin{array}{l}\text { The syringe should be fixed in a well-studied manner in } \\
\text { order to increase the quality of the printed parts }\end{array}$ \\
\hline Customization and modern design & The customers say it must look good and customized \\
\hline Optimize the size of the extruder & Extruder takes up little space in the BCN 3D machine \\
\hline $\begin{array}{l}\text { Optimize the forces applied to the } \\
\text { machine }\end{array}$ & $\begin{array}{l}\text { The forces applied by the extruder on the 3D printing } \\
\text { machine must be optimized }\end{array}$ \\
\hline Use a maximum of standard elements & $\begin{array}{l}\text { The solution must use standard parts of exchange so as not } \\
\text { to increase the price and also for the availability of the parts } \\
\text { in the market }\end{array}$ \\
\hline Use available resources & $\begin{array}{l}\text { Teachers, technicians, students, and laboratories should have } \\
\text { the opportunity to implement the solution easily without the } \\
\text { necessary prerequisites. In addition, the extruder to be } \\
\text { developed must not be implemented at the expense of the } \\
\text { financial resources of the institution, or at least not be very } \\
\text { demanding in terms of costs. }\end{array}$ \\
\hline Easy to produce & $\begin{array}{l}\text { Assembly and disassembly of the extruder must be easy and } \\
\text { fast }\end{array}$ \\
\hline Easy maintenance & $\begin{array}{l}\text { The solution must be designed and implemented to make } \\
\text { maintenance easy }\end{array}$ \\
\hline Clean up quickly and efficiently & The solution must be easy to clean \\
\hline
\end{tabular}

Step 2: Technical Descriptors - "Voice of the Engineer": Among the defined quality characteristics for the ceramic extruder are:

- Pressure: pressure needed to get the ceramic paste out,

- Effort: number of turns or time or effort needed to move the plunger of the syringe,

- Pleasing appearance: based on customer survey results,

- Cost to produce: cost to manufacture the ceramic extruder,

- Time to develop: time needed to develop the ceramic extruder,

- Counter space: the amount of counter space occupied by ceramic extruder,

- Volume: volume of the part to be printed, 
- Structure's material: nature of the material used (percentage of ceramics, percentage of binder),

- Color: different colors used to print parts of ceramic.

- Weight: weight of the ceramic extruder to be developed,

- Time: time to set and adjust the syringe.

All the technical specifications are shown in Fig. 5.

Then, a determination must be made as to the direction of movement for each descriptor (direction of improvement). The orientations at the base of each column of this matrix indicate how gains can be made for each of the specifications (Maximize the level $(\uparrow)$, minimize the level $(\downarrow)$, and get the desired level (o)).

Below are examples to explain how to reach the orientation for some specification:

- Minimizing the cost of development is an advantage for the design team so the orientation of the specification "cost to produce the extruder" is down $(\downarrow)$.

- The goal of the project is to print large parts, so to achieve the goal; the specification "volume" must be maximized. The orientation is upwards $(\uparrow)$.

- To increase the quality of the part printed by the ceramic extruder, it is necessary to fix the syringe with certain well-defined methods; so the orientation of the specification "fixing method" has a target value (o).

If the sense is not obvious, then the specification is not clear. Note that, the operationalization of Hows is the How Muchs. The How Much's should be measurable as much as possible [54].

Step 3: Characterize the technical Descriptors - "Voice of the Engineer": In order to rate the design characteristics in terms of technical difficulties, the weights are generally based on given Likert scale from 1 to 5 , as $1=$ Too easy; 2 = Easy; 3 = A bit difficult; $4=$ Difficult; $5=$ Very difficult. For example, a weight of 4 (difficult) was given to "pressure criterion" since the determination of the pressure is not an obvious thing, because it has a direct relationship with the volume of the syringe. It requires mechanical calculations in order to use the recommended pressure to print good quality parts. However, minimizing the counter space of the customized extruder is not easy at all. Since proposing an extruder that will answer all the requests of the customers and which is of small dimension requires a lot of design work, the group assigned a weight of 5 (very difficult) to this criterion.

Step 4: Relationship Matrix: In this step, the relationship between customer needs and the design's ability to meet those needs was determined. This was done by filling in the central matrix as shown in Fig. 5. The following question was asked, "What is the strength of the relationship between the technical descriptors and the customers' needs?"

In this step, each cell of the form represents how an engineering specification relates to a customer's requirement. The relation is conveyed through specific symbols or numbers: strong relationship (9, or a black disk with a white dot inside), medium relationship (3, or a circle), weak relationship ( 1 , or a triangle), and ( $0=$ no relationship at all, or the cell is left blank). Different symbols may even be used [55]. For example:

- The customer requirement "Print hip prosthesis and various ceramic parts" has a strong relationship (9) with the technical descriptors "volume, structure's material, color, counter space and continuous working time" because the customized extruder must print small parts, larger parts, parts with different material structures, etc. However, we want an architecture that will meet all these requirements but at the same time minimize the counter space of the extruder and allow the continuity of printing to get parts with high quality. 
- To achieve the customer demand "Install the extrusion system on the BCN3D machine”, we must take into consideration its architecture like counter space of the extruder and its weight, energy, and software used, as well as the attachment system (how the extruder will be attached to the machine BCN3D printer). This explains the strong relationship mentioned in Fig. 5.

Usually, numerous customer demands are generated initially. And then, to save work, the least important ones are discarded. However, the discarded items should be recorded to assure future designers that these customer demands were indeed considered. If any row of this matrix is blank, then the satisfaction of that customer demand cannot be assured. That demand, therefore, should either be eliminated or another quality characteristic should be added [53].

Step 5: Correlation matrix: In this step, it is examined how each of the technical descriptors affects each other. Strong negative relationships between technical descriptors need to be documented, and physical contradictions should be eliminated [56]. The assignment of positive or negative correlations is based on the influence of How's on achieving other How's regardless of the direction in which the How Much values move. Positive correlations are those in which one How supports another. The other way, negative correlations are those in which one how adversely affects the achievement of another how. These conflicts are extremely important as they represent conditions to direct trade-offs [54].

The main trends in the project matrix are as follows:

- When trying to increase performance in general, the cost of the prototype is affected.

- The volume of the syringe has a direct impact on pressure used to flow the raw material, and also on the continuity of printing.

- The continuity of printing is correlated to the innovative solution and the adjustment time of the syringe.

- Time to develop the solution is correlated to the availability of materials, software, and energy.

If two specifications are dependent, a symbol is written in the intersection. There are many different styles of symbols used, the simplest method is to use a "+" to denote that improvement in meeting one of the specifications will improve the other (they are synergistic), and use a "-" to show that improvement in meeting one may harm the other (a compromise may be forced). Some use ++ and - to show a strong dependency.

Step 6: Customer Rating of the Competition: This concerns only with a subjective comparison that is based on customer opinion. In this stage, the first step is to identify the benchmarks. We are redesigning this product, so the current product is the first benchmarks, the second one is ZMorph Thick Paste Extruder [57]. It has 30 to $100 \mathrm{ml}$ syringes as their material reservoirs, but what they gain in volume, they lose in performance and precision [24], and the third one is a clay paste extruder, which was inspired by an air-pressure has driven solder paste depositor. The body of the extruder is a syringe filled with clay paste. When pressurized, the paste is pushed out of the extruder at a near-constant rate [58].

This method is of strategic importance to know how the product of a competitor matches up to the customer requirements compared with our product. Competitive benchmarking answers the question "WHY" we should focus on which requirements and will allow a plan to be derived for improvement. The benchmarking on technical performance reveals our technical position with respect to competitors [54]. This comparison is shown in Fig. 5.

Firstly, for each customer's requirement, the existing design is rated on a scale of 1 to 5 . The product does not meet the requirement at all (1), slightly (2), somewhat (3), mostly (4), and completely (5). 
Then, a "priority (0-1)" part is added near "weighting" to mention priority functions for product success. This step shows opportunities for product improvement. If all the competition ranks low on one requirement, this is clearly an opportunity. This is especially so if the customers ranked that specific requirement highly important.

If the competing products rank high on an important requirement, it is recommended not to change the features that helped it meet that requirement. This step in the QFD method can help avoid needless work and product weakening.

Among the important points to note are:

- The competitors allow flow stability when pushing the raw material from the syringe and use standard energy sources. It should be studied what makes this work well.

- The products have a poor capacity to print various parts (volume, structure's material...) and to adapt to other machines. Clearly, this is a market opportunity.

- For customization and modern design requirement, neither of the competitors score above 3, leaving room for the development of a superior product in this area. 


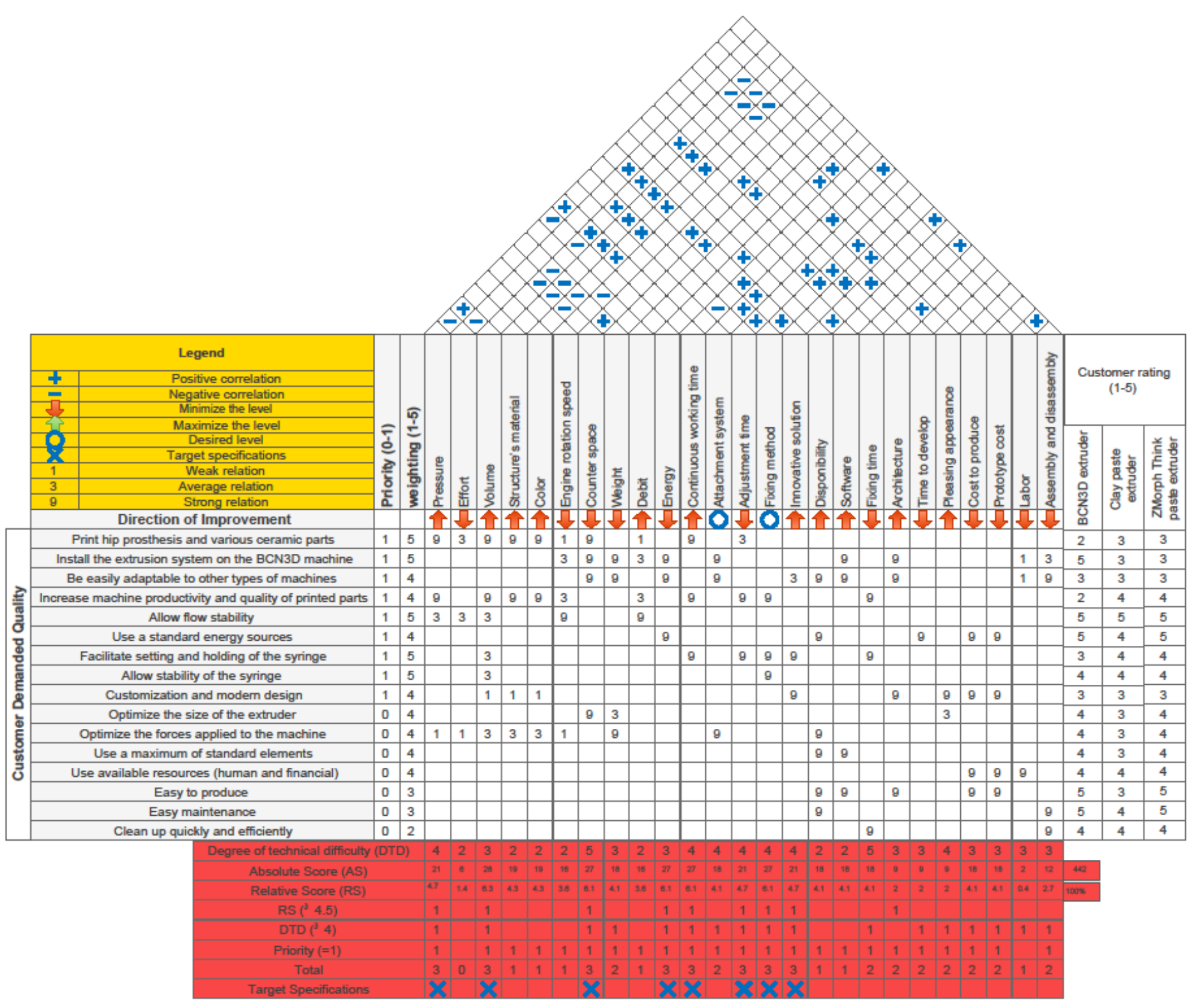

Fig. 5. The House of Quality (HOQ) to improvement of extrusion system of 3D printer for ceramic 
Step 7: Specification Importance: In the development of products, it is seldom that all targets can be met in the time available and so this matrix helps guide what to work on. For this reason, attention must be paid to the specifications with the highest scores. Therefore, the goal of this step is to determine the importance of each specification.

The method to find importance is as follows:

1. For each specification multiply the importance priority (0-1) from step 6 (Customer Rating of the Competition) with the 0-1-3-9 relationship values from step 4 (Relationship Matrix) to get the weighted values.

2. Sum the weighted values for each specification. For example, in Fig. 5:

- The score for specification "pressure" is $9 \times 1+9 \times 1+3 \times 1+1=21$.

- The score for specification "continuous working time" is $9 \times 1+9 \times 1+9 \times 1=27$.

3. Normalize these sums across all specifications. The sum across all the specifications is 442 so, for example:

- "Pressure" specification has an importance of 21/442=4.75\%.

- "Continuous working time" has the importance of $27 / 442=6.1 \%$.

4. In the lower part of the QFD matrix, each specification is given three ratings:

- High relative score (RS): score of 1 or 0,1 being assigned to a high PR ( $\geq 4.5 \%)$. For example, "pressure" specification has a high relative score (RS) of 1 because its relative score is $4.75 \geq 4.5 \%$, and "effort" specification has a high relative score (RS) of 0 because its relative score is $1.48 \leq 4.5 \%$.

- High degree of difficulty (DDT): rating of 1 for values of 4 or 5 . For example, "pressure" specification has a high degree of difficulty (DDT) of 1 because its degree of difficulty is 4 , and "effort" specification has a high degree of difficulty (DDT) of 0 because its degree of difficulty is 2 .

- Priority: the rating of 1 if the specification is derived from a function that has been identified as a design priority in the comparative survey. For example, "pressure" specification has a priority rating of 1 because it is derived from a requirement "print hip prosthesis and various ceramic parts" which is identified as a design priority in the comparative survey, and "effort" specification has a priority rating of 0 because it is derived from a requirement "optimize the size of the extruder" which is not a priority requirement.

Finally, a rating out of 3was obtained, indicating that they are the specifications which are both important for the customer, difficult to achieve technically, and which have the highest interaction with the other specifications. Table 2 shows the most important specifications.

Table 2.

The most important specifications for designing the new extrusion system

\begin{tabular}{ll}
\hline Function & Definition \\
\hline $\begin{array}{l}\text { Pressure } \\
\text { Volume }\end{array}$ & $\begin{array}{l}\text { The pressure required to circulate the ceramic material through the syringe } \\
\text { It is the volume of the printed parts which has an impact on the dimensions of the } \\
\text { syringe used for printing } \\
\text { The size of the extrusion system that must necessarily be respected in order to } \\
\text { install it on the BCN3D printer machine }\end{array}$ \\
$\begin{array}{l}\text { The energy source used for the extrusion system to work in the best conditions } \\
\text { Energy }\end{array}$ & $\begin{array}{l}\text { The extrusion system must print continuously whether it is small or large parts } \\
\text { time }\end{array}$
\end{tabular}

Adjustment time

This is the time required to make adjustments or to change the empty syringe with 
Fixing method

Innovative solution another one filled with ceramic material in order to print continuously The method of attachment of the syringe and extrusion system should be simple to easily allow changing of the syringe during printing and adaptation to other machines

Our solution must certainly be innovative and optimize

Also,those DDT is equal to 5 whose score is 2 have to be kept, especially if it is a customer expectation like a specification "fixing time".

These specifications and requirements allow understanding the design problem of the custom extruder. These requirements were usedas a basis for generating concepts that will lead to a quality extruder to print hip prosthesis and various printers' parts with the Morphological Matrix.

\subsection{Functional decomposition and concept variant generation using Morphological Matrix}

According to the requirements of the customers, the main objective of this extruder machine is to continuously print prostheses and other large pieces $\left(20 \mathrm{~cm}^{3}\right)$. Therefore, our design effort must be applied to improve:

1. The syringe tool that should operate with a wide range of parts (volume, structure's material and colors),

2. The mechanism that provides the necessary pressure to extrude the paste.

These two subsystems (syringe and force reduction) were at the center of the new design effort, as the design team wanted to rethink them to make the extruder more productive. This decomposition is designed to further the functional requirements that have become the basis for the concept generation technique. It aids to transform the functions into concepts. It is important to remember that function tells what the product must do, whereas its form, or structure, conveys how the product will do it.

The goal of this step is to generate as many concepts as possible for each of the subsystems identified in the decomposition. It should be noted that the concepts in the morphology are abstract in that they have no specific geometry. Rough sketches of these concepts and words are both used to describe the concept.

\subsection{1. $\quad$ Syringe tool subsystem}

Regarding the syringe subsystem, there are five ways to print the prostheses and large parts, as shown in table 3.

Concept 1: The first concept is to use a syringe of $5 \mathrm{~cm}^{3}$ as shown in Table 3 . The idea is to print the hip prosthesis using several $5 \mathrm{~cm}^{3}$ syringes. It is a charger of four syringes of $5 \mathrm{~cm}^{3}$ or more, once mixing in the first syringe is completed, the system will make an automatic change to print with the second syringe and so on.

This system allows printing large parts with different materials and colors because we can fill each syringe can be filled with different materials or colors. It is an innovative solution since so far there is no commercial DIW printer equipped with a syringe loader. The use of a $5 \mathrm{~cm}^{3}$ syringe makes it possible to keep the current reduction system since the dimensions of the syringe will not be changed.

Concept 2: The second is to use a single syringe of $20 \mathrm{~cm}^{3}$ as shown in table 3 . This one allows printing large parts. However, this solution limits printing with different colors and materials in the same part. 
Concept 3: The idea in this concept is to use a loader like the first concept but with $20 \mathrm{~cm}^{3}$ syringes, in order to minimize the time to change the syringe.

Concept 4: Another option is to use a loader of various syringes. For example, $5 \mathrm{~cm}^{3}$ and 20 $\mathrm{cm}^{3}$, in order to print small parts or large parts as needed. This solution also allows printing with different materials and colors. For this concept, the use of a variable speed drive is essential.

Concept 5: For this concept, to print pieces of $20 \mathrm{~cm}^{3}$ or more, in addition to a syringe a tank will be used, in which the soft material is located. The tank is outside the machine, so the extrusion system will not be changed. This system is inspired by the machine Delta WASP clay [59] which includes a 3-l tank (or 5-l on request) for holding the highly viscous clay material. The tank is equipped with a piston that effectively pushes the clay paste through the tank and into a $12 \mathrm{~mm}$ diameter Teflon pipe which is connected to the $1.2 \mathrm{~mm}$ extruder. WASP also claims that the combination of a screw extruder and a pressure extruder is capable of reaching precision levels comparable to polymer extruders. This novel structure also allows users to pause and restart the extrusion flow of the material [59].

\subsubsection{Force reduction subsystem}

The objective of the present design is to print prostheses with a volume of $20 \mathrm{~cm}^{3}$ or more. That is why the dimension of the syringe should be changed. Since the pressure is constant if the surface increases it is necessary to increase the force. For this reason, it is to change the force reduction subsystem.

There are various concepts proposed as mentioned in table 3: Sketches of each concept were used. They are very useful because they allow remembering functions by their shapes and they provide a clear record of the development of the concept and the product [52].

Concept 1: The first concept concerns the same reduction system used in the current BNC3D printing machine. It is a gear system that allows applying a force on the syringe plunger to push the flexible material and deposit it on the bed of the 3D printer layer by layer. A gear stage must be added to increase the force applied to the plunger to print large parts.

Concept 2: In order to push the ceramic material a simple system can be used (drive-screw and nut mechanism) like the one used by the Zmorphmachine [60]. For the type of this device that uses an electric motor, the rotation (the axis of the motor rotates) is transformed into linear translation using a drive-screw and nut mechanism. This concept must have a larger footprint to apply the proper force.

Concept 3: The idea in this concept is to use a wheel screw nut system to push the plunger of the syringe.

Concept 4: A planetary gear system has lots of advantage as compared to traditional gearboxes (concept 1 ) because:

- It will assure a higher gear ratio in compact space.

- Power transmission efficiency will be quite good as compared to traditional gearboxes i.e. higher proportion of input energy will be delivered with the help of such gearing arrangement.

- The planetary gear system will have higher torque transmission capability and will have lower inertia.

- The load that is being transmitted will be shared among multiple planet gears, hence load distribution will be quite good and torque transmission will be increased by using planetary gearing arrangement. 
- In the case, driving member and driven member are concentric and therefore driving and driven types of equipment could be installed in the same line which will result in space-saving.

Concept 5: The soft material accumulates in a syringe and was inspired by an air-pressure (pneumatic system) driven solder paste depositor. The body of the extruder is a $20 \mathrm{ml}$ syringe filled with paste. When pressurized, the paste is pushed out of the extruder at a near-constant rate. Sophisticated versions of this concept are used widely in industry, but their cost is $2-3 \mathrm{x}$ that of the printer itself.

Concept 6: For this purpose, a large number of pumps are used in the $3 \mathrm{D}$ printing for ceramic industry [24]:

- Gear pumps: Gear pump belongs to the positive displacement pumps group. The pump has a small rotor mounted eccentrically within a larger external gear and when the rotor is driven, the gear also rotates.

- Lobe pumps: The lobe pump is a positive displacement rotary pump. The upper lobe is driven by the motor shaft. The lower lobe is located on the driveshaft and is operated with a helical gear. Both lobes turn synchronously without touching each other. When the pump is running, they move a fixed volume of liquid.

- Progressive cavity pumps: Progressive cavity pumps, sometimes called eccentric screw pumps, have only one rotor part. Rotor works within a flexible rubber stator, which has double internal helices. The difference in pitch forms sealed cavities between the rotor and the stator cause an axial flow of the material. Progressive cavity pumps are used for practically all types of liquids from very fluid to highly viscous.

- Peristaltic pumps: Peristaltic pumps transport material by mechanically squeezing the space enclosed by the flexible tube. The pump works on the principle of rotating rollers or cams acting directly upon the tube containing the pumped material.

In the future, one of the six concepts will be developed in detail.

Table 3

Morphological matrix for syringe and force reduction subsystem

\begin{tabular}{cccc}
\hline Subsystems & Syringe subsystem \\
Loader of 4 or more syringes \\
Printing with a $5 \mathrm{ml}$ syringe \\
Concept 1
\end{tabular}




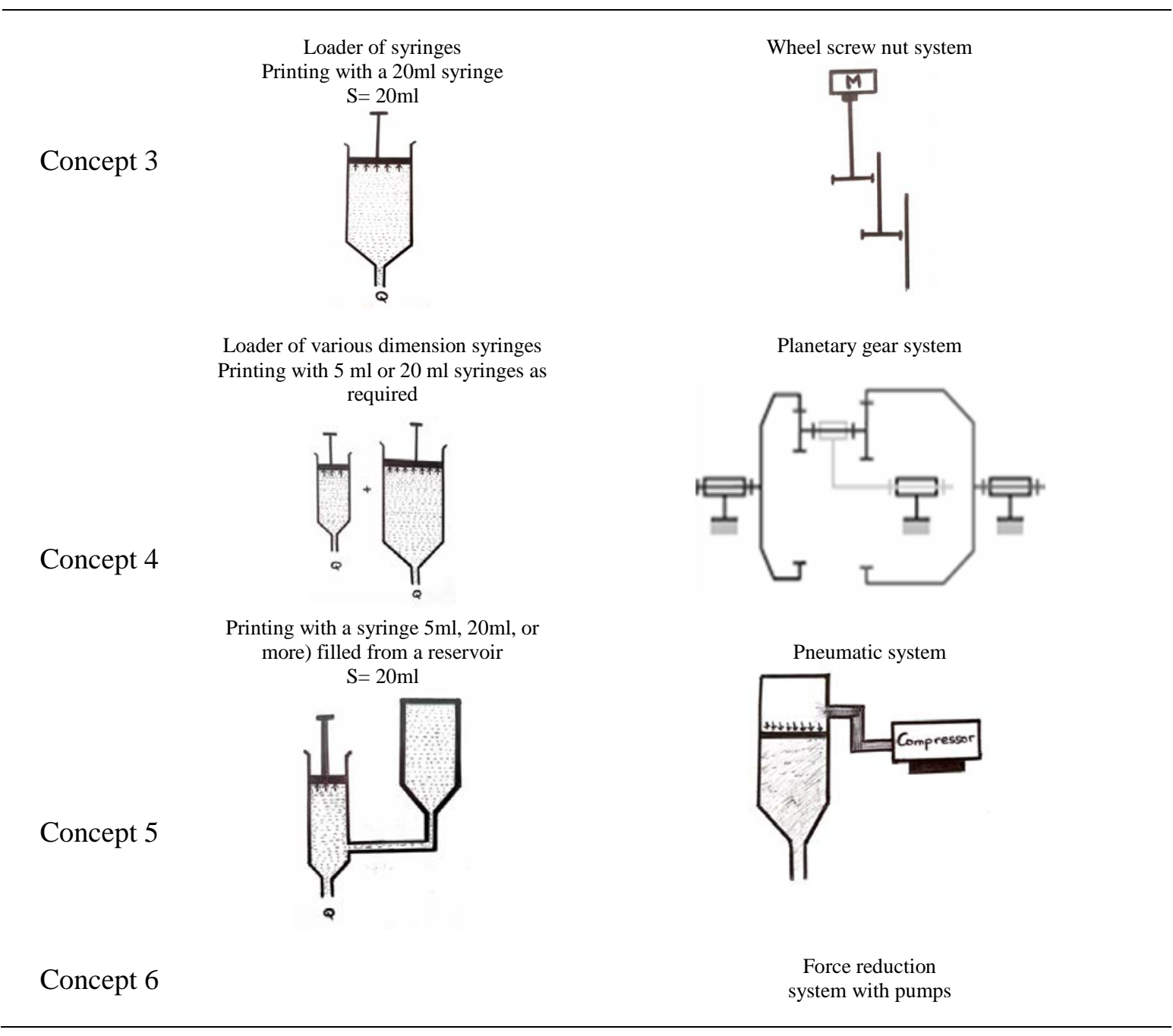

\section{Conclusions and prospects}

The objective of this paper was to develop the first steps of the redesign of a new type of ceramic-paste extruder system able to print bulky ceramic prostheses such as the human hip. It is based on the plunger extrusion mechanism of a paste extruder and can easily be adapted to other low-cost 3D machines, which extends the access of this technology to a larger number of designers. The original extruder was very limited when printing voluminous parts because this task was impossible without stopping the printing process in order to refill the barrel, which was negatively reflected in the quality of the final product. Then, the design challenge was to satisfy this main function while combining the maximum performance criteria, mainly quality, adaptability and flexibility, the diversification of materials to be deposited, productivity and to have a competitive product compared to these similar products. For this purpose, a rigorous customized product development process was used, based on design tools.

Quality Function Deployment method allowed generating the target specifications of the paste extruder. Among the most important specifications are pressure (required to circulate the ceramic material through the syringe), volume (of the printed parts, which has an impact on the dimensions of the syringe used for printing), and footprint (the size of the extrusion system that must necessarily be respected to be fitted with standard 3D printers). Thereafter, the application of the design conceptual with the morphological matrix shows that the generated solution concepts can guarantee the design of a new productive mechanism for continuous printing parts with a large size and with different colors and materials simultaneously. Future directions could 
be summarized as follows. Firstly, comparing the alternative concepts generated by the morphological matrix among them, based on the assessment criteria found by the quality function deployment to which they must respond. The techniques used helped to choose, among all the global concepts found, which one will be put forward in priority.

In future works, the decision matrix method, or the Pugh method (design conceptual step)will be used to compare, concept alternatives. Secondly, the execution of the 3D Design of the extruder and selection of the appropriate materials will be performedfor each element, followed by the dimensioning and tolerancing phases. This process includes the affectation of GDT (Geometric dimensioning and tolerancing) and surface roughness and also the calculation of parameters, such as forces, loads, pressure, etc. Then, the prototype of the designed extruder 3D will be manufactured and validated with experimental tests. Finally,the possibility of hybridization of this ceramic paste extruder with that of based on the extrusion of filament, fused filament fabrication (FFF) in the same machine will be investigated.

\section{Declaration of competing interest}

The authors declare that they no known competing financial interests or personal relationships that could have appeared to influence the work reported in this paper.

\section{Acknowledgements}

The authors thank Ramón Casado-López for his help with the experimental tests of the ceramic printer.

\section{References}

[1] Chen Z, Li Z, Li J, Liu C, Liu C, Li Y, Wang P, Yi H, Lao C, Yuelong F (2019) 3D printing of ceramics: A review. $\quad$ European doi.org/10.1016/j.jeurceramsoc.2018.11.013.10.1016/j.jeurceramsoc.2018.11.013.

[2] Gonzalez GJ, Cano S, Schuschnigg S, Kukla C, Sapkota J, C. Holzer, « Additive Manufacturing of Metallic and Ceramic Components by the Material Extrusion of Highly-Filled Polymers: A Review and Future Perspectives », Materials, vol. 11, n 5, p. 840, mai 2018, doi: 10.3390/ma11050840.

[3] ISO/ASTM 52900 (2015) Additive manufacturing-General principles-Terminology. https://www.iso.org/standard/69669.html/, 2015. Accessed 10 January 2020.

[4] Marcus HL, Beaman JJ, Barlow JW, Bourell DL (1990) Solid freeform fabrication. Powder processing.

[5] Sachs E, Cima M, Cornie J (1990) Three-Dimensional Printing: Rapid Tooling and Prototypes Directly from a CAD Model. CIRP Annals. doi:10.1016/S0007-8506(07)61035-X.

[6] Yan Q, Dong H, Su J, Han H, Song B, Wei Q, Shi (2018) A Review of 3D Printing Technology for Medical Applications. Engineering. doi:10.1016/j.eng.2018.07.021.

[7] Paul GM, Rezaienia A, Wen P, Condoor S, Parkar N, King W (2018) Medical Applications for 3D Printing: Recent Developments. Missouri State Medical Association 115: 75-81.

[8] Corral IB, Rojo OP, Bagheri A, Canel JM (2017) Modelling of porosity of 3D printed ceramic prostheses with grid structure. Procedia Manufacturing. doi:10.1016/j.promfg.2017.09.183.

[9] Kim SH, Shin WB, Baek SW, Yoon JS (2019) Semiautomated fabrication of a custom orbital prosthesis with 3-dimensional printing technology. The Journal of Prosthetic Dentistry. doi:10.1016/j.prosdent.2019.03.021.

[10] Ventola CL (2014) Medical Applications for 3D Printing: Current and Projected Uses. MediMedia USA, Inc 39: 704-711.

[11] Elahinia MH, Hashemi M, Tabesh M, Bhaduri SB (2012) Manufacturing and processing of NiTi implants: A review. Progress in Materials Science. doi:10.1016/j.pmatsci.2011.11.001.

[12] Daniel B, Alexis I (2019) 3D-Printing of High-Strength and Bioresorbable Ceramics for Dental and Maxillofacial Surgery Applications-the LCM Process. Ceramic Applications 7:38-43.

[13] Derby B (2015) Additive Manufacture of Ceramics Components by Inkjet Printing. Engineering. doi:10.15302/J-ENG-2015014. 
[14] Zhou Z, Cunningham E, Lennon A, McCarthy HO, Buchanan F, Dunne N Development of threedimensional printing polymer-ceramic scaffolds with enhanced compressive properties and tuneable resorption. Materials Science and Engineering: C. doi:10.1016/j.msec.2018.08.048.

[15] Qian B, Shen Z (2013) Laser sintering of ceramics. Journal of Asian Ceramic Societies. doi: 10.1016/j.jascer.2013.08.004.

[16] Gu D, Wang H, Chang F, Dai D, Yuan P, Hagedorn YC, Meiners, W (2014) Selective Laser Melting Additive Manufacturing of TiC/AlSi10Mg Bulk-form Nanocomposites with Tailored Microstructures and Properties. Physics Procedia. doi:10.1016/j.phpro.2014.08.153.

[17] Sing SL, Yeong WY, Wiria FE, Tay BY, Zhao Z, Zhao L, Tian Z, Yang S (2017) Direct selective laser sintering and melting of ceramics: a review. Rapid Prototyping Journal. doi:10.1108/RPJ-112015-0178.

[18] Griffin C (1994) Daufenbach J, McMillin S (1994) Desktop manufacturing: LOM vs pressing. Am. Ceram. Soc. Bull. 73:109-113.

[19] Ghazanfari A, Li W, Leu MC, Hilmas GE (2016) A Novel Extrusion-Based Additive Manufacturing Process for Ceramic Parts. Proceedings of the SFF Symposium, Austin, TX 15091529.

[20] Händle F, (Ed.), (2007), Extrusion in Ceramics, Engineering Materials and Processes. doi:10.1007/978-3-540-27102-4.

[21] Amza C, Zapciu A, Popescu D (2017) Paste Extruder-Hardware Add-On for Desktop 3D Printers, Technologies. doi:10.3390/technologies5030050.

[22] Li W, Ghazanfari A, Leu MC, Landers RG (2017) Extrusion-on-demand methods for high solids loading ceramic paste in freeform extrusion fabrication. Virtual and Physical Prototyping. doi:10.1080/17452759.2017.1312735.

[23] Universal Paste Extruder for 3D printers. https://www.thingiverse.com/thing:20733, 2012. Accessed 10 January 2020.

[24] Pusch K, Hinton TJ, Feinberg AW (2018) Large volume syringe pump extruder for desktop 3D printers. HardwareX. doi: 10.1016/j.ohx.2018.02.001.

[25] Vojtech L (2015) Conception, Design and Materialisation of a pumping-based extrusion system for food 3D-printing. Polytechnic University of Catalonia: School of Industrial Engineering Department of Mechanical Engineering. Project Report.

[26] Ertay T, BüyüközkanG, Kahraman C, Ruan D (2005) Quality function deployment implementation based on analytic network process with linguistic data: An application in automotive industry, Journal of Intelligent and Fuzzy Systems 16:221-232.

[27] Kamara JM, Anumba CJ (2001) ClientPro: a prototype software for client requirements processing in construction. Advances in Engineering Software. doi: 10.1016/S0045-7949(00)00142-5.

[28] Abdul-Rahman H, Kwan CL, Woods PC (1999) Quality function deployment in construction design: application in low-cost housing design. International Journal of Quality \& Reliability Management. doi: 10.1108/02656719910268198.

[29] Charteris W (1993) Quality function deployment: a quality engineering technology for the food industry. International Journal of Dairy Technology. doi: 10.1111/j.1471-0307.1993.tb00852.x.

[30] Swackhamer R (1985) Responding to customer requirements for improved frying system performance. Food Technology 49:151-152.

[31] Vongvit R (2015) Using the Fuzzy-QFD for Product Development: A Case Study for 3D Printer. Applied Mechanics and Materials. doi: 10.4028/www.scientific.net/AMM.789-790.1196.

[32] Caligiana G, Liverani A, Francia A, Frizziero L, Donnici G (2017) Integrating QFD and TRIZ for innovative design. Journal of Advanced Mechanical Design, Systems, and Manufacturing. doi: 10.1299/jamdsm.2017jamdsm0015.

[33] Efstathiadis A, Koidis C, Tzetzis D, Kyratsis P (2018) Comparative study and analysis on themechanical properties of 3D printed surgicalinstrument for in-space applications. AcademicJournal of Manufacturing Engineering 16:26-32.

[34] Cordeiro, E.C., Barbosa, G.F. \&Trabasso, L.G. A customized QFD (quality function deployment) applied to management of automation projects. Int J Adv ManufTechnol 87, 2427-2436 (2016). https://doi.org/10.1007/s00170-016-8626-0.

[35] Sousa-Zomer, T.T., Miguel, P.A.C. A QFD-based approach to support sustainable product-service systems conceptual design. Int J Adv Manuf Technol 88, 701-717 (2017). https://doi.org/10.1007/s00170-016-8809-8.

[36] Ulrich KT, Eppinger SD. Product Design and Development, fifth ed., McGraw-Hill Education (2011).

[37] Kasaei A, Abedian A, Milani AS (2014) An application of Quality Function Deployment method in engineering materials selection. Materials \& Design. doi: 10.1016/j.matdes.2013.10.061. 
[38] Pahl G, Beitz W, Feldhusen J, Grote KH (2007) Engineering Design-A Systematic Approach. doi:10.1007/978-1-84628-319-2.

[39] Pugh S, Total design: integrated methods for successful product engineering, Addison-Wesley Publishing Company, Wokingham, England (1991).

[40] EL Mesbahi J, Rechia A, EL Mesbahi A, Kojmane A (2018) proposed design process of a customized educational hybrid prototyping machine, Proceeding of $5^{\text {th }}$ International IEEE Congress on Information Science and Technology, Marrakech, Morocco 342-347

[41] Zimmerman J, Evenson S, Forlizzi J (2004) Discovering and Extracting Knowledge in the Design Project. In Proceedings of Future Ground. Design Research Society.

[42] Dym CL (1994) Teaching Design to Freshmen: Style and Content. Journal of Engineering Education. doi: 10.1002/j.2168-9830.1994.tb00123.x.

[43] Khandani S (2005) Engineering Design Process. Education Transfer Plan.

[44] Bettencourt L, Ulwick AW (2008) The Customer-Centered Innovation Map, Harvard Business Review.

[45] Kiran DR. Total Quality Management: key concepts and case studies, 1st Edition, ButterworthHeinemann (2016).

[46] Arciszewski T (2018) Morphological Analysis in Inventive Engineering. Technological Forecasting and Social Change. doi: 10.1016/j.techfore.2017.10.013.

[47] Chan LK, Wu ML (2002) Quality function deployment: A literature review, European Journal of Operational Research. doi: 10.1016/S0377-2217(02)00178-9.

[48] Carnevalli JA, Miguel PC (2008) Review, analysis and classification of the literature on QFDTypes of research, difficulties and benefits. International Journal of Production Economics. doi: 10.1016/j.ijpe.2008.03.006.

[49] Sharma JR, Rawani AM, Barahate M (2008) Quality function deployment: a comprehensive literature review. IJDATS. doi: 10.1504/IJDATS.2008.020024.

[50] Temponi C, Yen J, Tiao WA (1999) House of quality: A fuzzy logic-based requirements analysis. EUR J OPER RES. doi: 10.1016/S0377-2217(98)00275-6.

[51] Bolar AA, Tesfamariam S, Sadiq R (2017) Framework for prioritizing infrastructure user expectations using Quality Function Deployment (QFD). International Journal of Sustainable Built Environment. doi: 10.1016/j.ijsbe.2017.02.002.

[52] Ullman DG, The Mechanical Design Process, Fourth Ed., Engineering Books, (2010).

[53] Bahill AT, Chapman WL (1993) A Tutorial on Quality Function Deployment, Engineering Management Journal. doi: 10.1080/10429247.1993.11414742.

[54] Govers CPM (1996) What and how about quality function deployment (QFD), International Journal of Production Economics. doi: 10.1016/0925-5273(95)00113-1.

[55] Akao Y (1900) Quality Function Deployment: Integrating Customer Requirements into Product Design-International Economy, first ed. Productivity Press.

[56] BRIEF, PRODUCT "Quality Function Deployment", 2012: Creative Industries Research Institute.

[57] Guidelines for Printing with Thick Paste Extruder », ZMorph Knowledge Base. http://support.zmorph3d.com/hc/en us/articles/115002218985-Guidelines-for-Printing-with-ThickPaste-Extruder, 2018. Accessed 23 December 2019.

[58] Arnone L (2014) Designing a Ceramic Printhead for a RepRap 3-D Printer. Swarthmore, PA: Swarthmore College Department of Engineering. Project Report.

[59] Delta WASPclay 3D printer lets you print high quality ceramic parts with ease. http://www.3ders.org/articles/20180130-delta-waspclay-3d-printer-lets-you-print-high-qualityceramic-parts-with-ease.html, 2018. Accessed 30 December 2019.

[60] ZMorph Thick Paste Extruder. https://www.reprap.me/zmorph-thick-paste-extruder.html. Accessed 30 December 2019. 